linear Zn(I)-Zn(0)-Zn(I) chain. Again, using the cadmium and mercury halides instead of $\mathrm{ZnBr}_{2}$ produced the $\mathrm{L}^{\star} \mathrm{ZnCdZnL}{ }^{\star}$ and $\mathrm{L}^{\star} \mathrm{ZnHgZnL}{ }^{\star}$ analogues, respectively.

\section{TETRAHYDROFURAN SYNTHESIS}

\section{Carbene reaction re-routed}

Angew. Chem. Int. Ed. http://doi.org/

f277mq (2015)

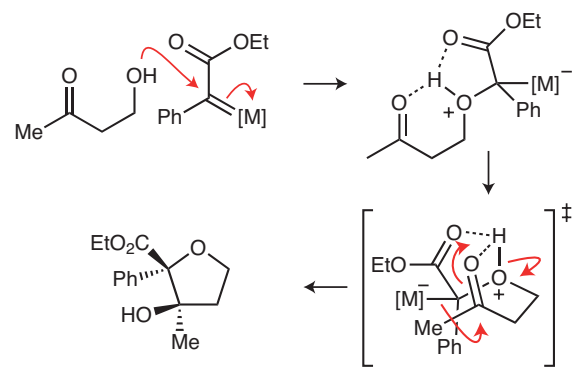

The tetrahydrofuran ring is widely found as a substructure in natural products; a recent review listed in excess of 30 such marine natural products, some of which display interesting antimicrobial, antibacterial and anticancer properties. Stereoselective routes to substituted tetrahydrofurans are thus in demand, but despite much attention from the synthetic community, the most highly substituted compounds remain difficult to access. Now, Christopher Moody and co-workers from the University of Nottingham have reported a method in which either a rhodium or copper catalyst directs the combination of diazocarbonyls and $\beta$-hydroxyketones to form these sought after products. The second of these starting materials are, of course, readily accessible by aldol reactions.

Moody and co-workers have long had an interest in $\mathrm{O}-\mathrm{H}$ insertion reactions of metallocarbenes. The tetrahydrofuran products appear - on paper - to be the result of an intramolecular aldol reaction after such an insertion reaction on the $\beta$-hydroxyketone starting material. Exposure of this apparent intermediate to the reaction conditions did not, however, result in the formation of any tetrahydrofuran product. It is proposed, instead, that an initially formed oxonium ylide (which may or may not first dissociate from the metal) undergoes an intramolecular cyclization to the tetrahydrofuran rather than the 1,2-H-shift that would result in the insertion product. Hydrogen bonding results in a well-ordered transition state for this process and explains the high observed diastereoselectivity.

The rhodium and copper catalysts seem to offer complementary reactivity - with rhodium working best with electron-rich diazoacetates and copper working best with electron-poor substrates. A variety of $\beta$-hydroxyketones substrates were studied, with rhodium catalysts found to be superior when these were secondary or tertiary alcohols. When catalysts with chiral ligands were used, those with rhodium resulted in essentially no chiral induction while those with copper gave low enantiomeric excess. This suggests that the key intermediate remains at least loosely bound to the metal in the case of copper while reactions with rhodium proceed through a metal-free intermediate.

\section{ENERGY STORAGE}

\section{Better together}

J. Am. Chem. Soc. http://doi.org/5z6 (2015)

As society's demand for energy gets ever larger, the development of technologies for both its efficient conversion and storage have become two of the most important goals for researchers today. Many of them are working towards the efficient conversion of solar energy, but given that the sun only shines for a portion of each day, energy for use during the hours of darkness must be stored post-conversion during the day. Storage and conversion systems tend to be separate, with solar cells converting light energy into electrical energy and batteries storing it in the form of chemical energy.

Now Yiying Wu and colleagues from Ohio State University have developed a device that integrates photoelectric conversion and energy storage. It brings together a lithium-iodine redox-flow battery and a dye-sensitized solar cell to create a system Wu and colleagues dub a 'lithium-iodine solar flow battery'. It features a lithium anode, a platinum counter electrode, a titania photoelectrode sensitized with a ruthenium-based dye and an $\mathrm{I}_{3}^{-} / \mathrm{I}^{-}$electrolyte. On discharge the device functions similarly to a standard Li-I battery, lithium is oxidized at the anode, $\mathrm{I}_{3}^{-}$is reduced to $\mathrm{I}^{-}$at the counter electrode and an electric current is generated.

The charging process, however, is slightly different. As in a standard set up, an external voltage is applied and $\mathrm{Li}^{+}$ions are reduced to metallic $\mathrm{Li}$ at the anode, however, the voltage is lower in comparison to that used in a conventional Li-I battery ( $2.9 \mathrm{~V}$ versus $3.6 \mathrm{~V}$ ). This is because recharging is assisted by the dye-sensitized titania. The dye molecules are photoexcited when illuminated and shed an electron into the conduction band of the titania electrode. The oxidized dye then reacts with $\mathrm{I}^{-}$to regenerate $\mathrm{I}_{3}{ }^{-}$, helping to complete the recharging cycle. The photo-assisted reduced-voltage recharging of this hybrid device thus makes energy savings of $20 \%$ over a conventional Li-I battery set-up.

Written by Gavin Armstrong, Stephen Davey, Claire Hansell and Anne Pichon.

\section{blog $_{\text {roll }}$ 空}

\section{Chemistry education}

Embedding scholarship into the teaching of chemistry.

With teaching quality high on the agenda, chemistry education research is beginning to emerge as a discipline within some chemistry departments. Tina Overton writes on the RSC's Education in Chemistry blog (http://go.nature.com/ dDEm4d) of the need to support staff who wish to carry out pedagogic research in chemistry departments, including supporting the development of expertise and creating a community of practice. In the case of the latter, chemists in the Twitterverse might like to follow and contribute to \#chemed.

Lots of expertise is available on the Staff and Educational Development Association blog, currently running a series called \#53ideas by Graham Gibbs. These are short posts on various thoughts and ideas that "teachers should know about" underpinned by substantial literature. Some of Gibbs's own work was with the chemistry department at Oxford. In a recent post (http://go.nature.com/ vEmgp1), he advocated a more pragmatic framework for programme design in lieu of distinct educational objectives.

Greg Ashman keeps a well-written blog on cognitive science (and educational research generally). His post on 'cognitive load theory' (http:// go.nature.com/cLx7mO) challenges some widely held assumptions about what 'guided instruction' is, raising the bar for all of us interested in improving student learning. Ashman's blog is one of the many compiled by the aggregating website The Echo Chamber (http:// go.nature.com/CMYNCJ) which is well worth a perusal to find decent blogs about education.

Back to chemistry: while the Compound Interest posters are deservedly well known, lots of use could be made of the This Week in Chemistry series (http://go.nature.com/ zZGnyZ). I'd love to see student-generated examples shared with \#TWIChem.

Written by Michael Seery, who blogs at www.michaelseery.com 